\title{
The Giant Caecum with No Apparent Reason: Ogilvie's Syndrome
}

\author{
Larissa de Oliveira, Gustavo Rengel dos Santos, Gustavo Lenci Marques, Felipe dos \\ Santos Dunin, Viviane de Hiroki Flumignan Zetola and Mauricio Carvalho \\ Internal Medicine Department. Hospital de Clínicas of Federal University of Parana, \\ Curitiba, Brazil
}

Correspondence should be addressed to: Larissa de Oliveira; larioliveira@ufpr.br

Received date: 4 September 2013; Accepted date: 1 November 2013; Published date: 17 December 2014

Academic Editor: Vedat Göral

Copyright (C) 2014. Larissa de Oliveira, Gustavo Rengel dos Santos, Gustavo Lenci Marques, Felipe dos Santos Dunin, Viviane de Hiroki Flumignan Zetola and Mauricio Carvalho. Distributed under Creative Commons CC-BY 3.0

\begin{abstract}
Acute colonic pseudobstruction (Ogilvie's syndrome) is a severe, life threatening condition characterized by acute colonic distension without evidence, or mechanical obstructive factor. Prompt detection results in an early colonoscopy treatment, which results in better prognosis. We report the case of a 57 year old female patient, with a previously diagnosed follicular lymphoma which presented with severe abdominal distention, impairing adequate thoracic expansion. The abdominal CT performed showed a significant dilatation of the cecum $(13.27 \mathrm{~cm})$, with no mechanical obstruction. A decompressive colonoscopy was performed, with immediate clinical response.
\end{abstract}

Keywords: Colonic pseudo-obstruction; colonoscopy; constipation; colonic decompression.

\section{Introduction}

Ogilvie's syndrome (acute colonic pseudoobstruction) is characterized by an intense dilatation of the caecum and right colon, which may extend to the rectum, in the absence of a mechanical obstructive cause. It is a relevant differential diagnosis when it comes to acute colonic distention, since if left unrecognized and untreated, the continued distension can lead to perforation that is associated with high mortality rates.

\section{Case Report}

A 57 year-old female patient diagnosed 4 years ago with stage IV follicular lymphoma presented with a seven-day history of constipation. The patient was using morphine, gabapentin, dipyrone, amitriptyline and prednisone. On admission, she was confused, pale, with persistent vomiting and abdominal

Cite this Article as: Larissa de Oliveira, Gustavo Rengel dos Santos, Gustavo Lenci Marques, Felipe dos Santos Dunin, Viviane de Hiroki Flumignan Zetola and Mauricio Carvalho (2014), " The Giant Caecum with No Apparent Reason: Ogilvie's Syndrome ", International Journal of Case Reports in Medicine , Vol. 2014 (2014), Article ID 662882, DOI: 10.5171/2014.662882 
distension that restricted her respiratory movements. A digital rectal examination did not reveal any impacted faeces. Laboratorial tests showed anaemia (haemoglobin of 7.8 $\mathrm{g} / \mathrm{dL})$, leukopaenia $\left(3,620\right.$ cells $\left./ \mathrm{mm}^{3}\right)$, and hyponatraemia $(130 \mathrm{mmol} / \mathrm{L})$. A nasogastric tube drained $1.75 \mathrm{~L}$ of stasis in 24 hours. Abdominal CT demonstrated severe dilatation, extending from the caecum, which had a diameter of $13.27 \mathrm{~cm}$, to the splenic flexure (figure 1a). The small bowel, rectum and sigmoid colon were normal, with no radiological evidence of wall thickening or distension. No mechanical obstruction was observed. She did not respond to neostigmine and was submitted to a decompressive colonoscopy.

There was elimination of a large amount of flatus and liquefied stools, with immediate improvement of distension and ventilation. A control CT, performed one week later, showed no abnormalities (figure 1b).

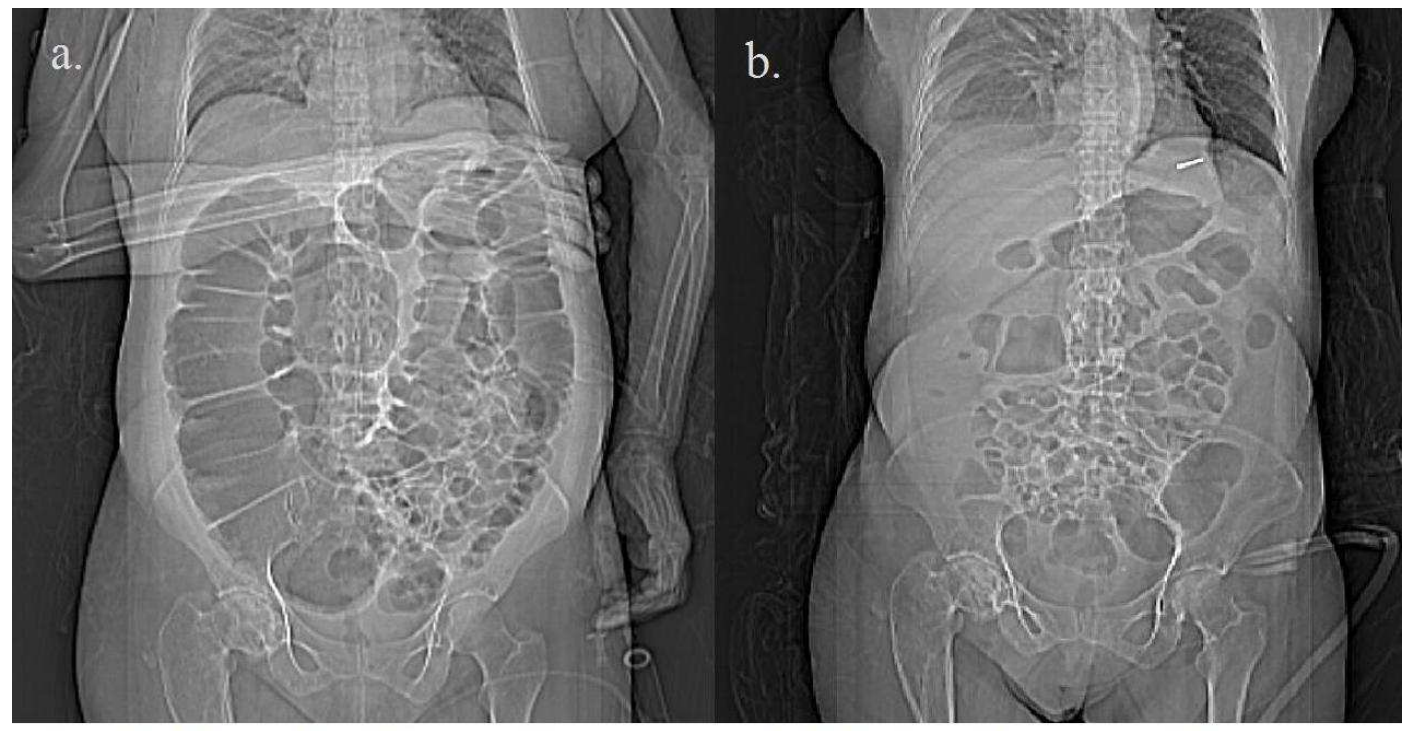

Figure 1. Abdominal and Thoracic CT topogram. At admission (a), with a increased diameter caecum and right colon, without evidence of left colon enlargement; (b) after decompressive colonoscopy, demonstrating regression of colonic dilation. 


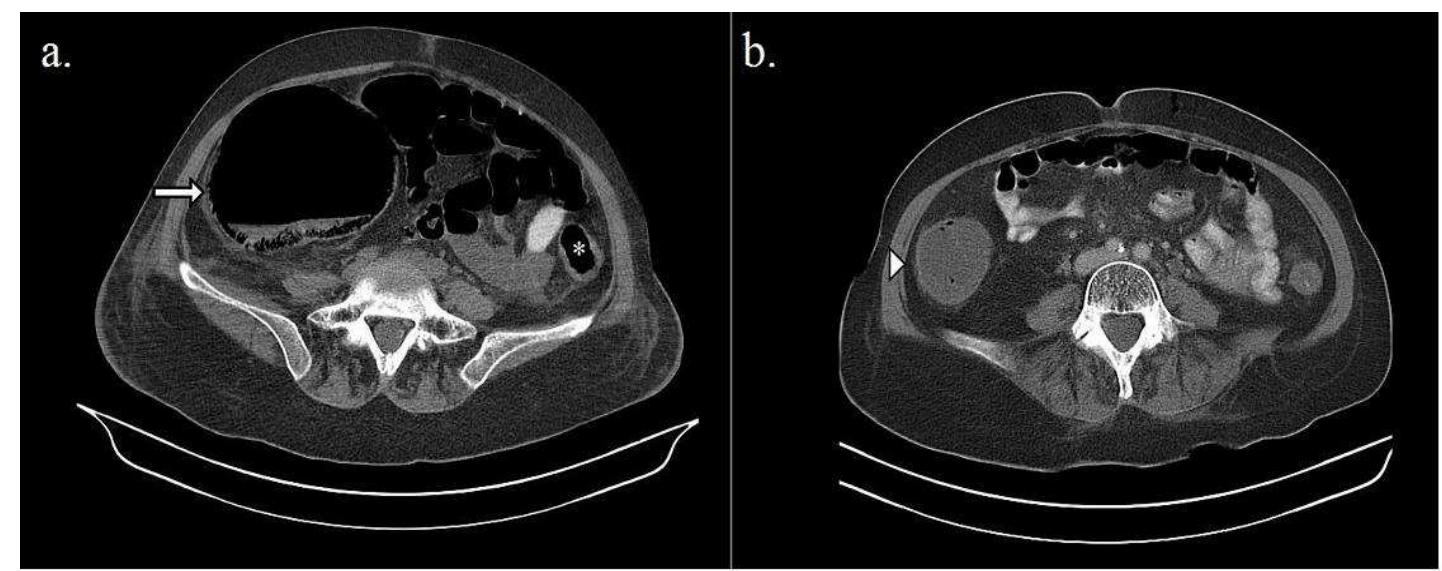

Figure 2. Abdominal CT scan in axial plan (a) at admission, demonstrating a cecum with $13.27 \mathrm{~cm}$ diameter (arrow), and left colon with normal aspect (asterisk); (b) after decompressive colonoscopy, showing the cecum (arrowhead) with a normal diameter $(4.77 \mathrm{~cm})$.

\section{Discussion}

Ogilvie's syndrome (acute colonic pseudoobstruction) is characterized by an intense dilatation of the caecum and right colon, which may extend to the rectum, in the absence of a mechanical obstructive cause. In about $95 \%$ of cases there is an underlying condition, most frequently trauma, infection or cardiac diseases. The pathogenesis of the syndrome is not completely understood.

Clinical manifestations include nausea, vomiting, abdominal pain, constipation and paradoxical diarrhoea. Abdominal distension is always present and may interfere with ventilation. Systemic toxicity signs usually appear in a late stage, when the risk of complications is high. Those include mural ischemia and perforation (according to Laplace's Law, there is an inverse relation between the diameter of a hollow viscus and the pressure needed to stretch its walls, which explains the elevated perforation risk in a dilated colon). CT is essential for demonstrating colonic dilatation and to exclude an obstructive factor. Although there may be a relationship between Ogilvie's syndrome and opioid usage, it differs from opioid induced constipation. In this case there is delay of gastrointestinal transit, stimulation of sphincters, and increased mucosal fluid absorption. These elements lead to faecal impaction on rectal ampulla. Supportive measures can be used when caecal diameter is less than $12 \mathrm{~cm}$ and the patient presents with no severe pain. Management of acute colonic pseudo-obstruction includes pharmacologic measures (mainly the intravenous administration of neostigmine, an acetylcholinesterase inhibitor) and colonoscopic decompression.

Pharmacologic treatment has been considered by a number of studies as a first-line option therapy. However, many of the studies investigating its use in Ogilvie's syndrome are small in size, lack control groups, use variable doses of neostigmine and do not review radiological response. Patients using motility reducing agents or with hydroelectrolytic disturbances usually have a poor response to neostigmine. Performing a decompressive colonoscopy seems to promote a better outcome, although there are important issues to consider when deciding to perform it. For example, to obtain effective endoscopic decompression at least the hepatic flexure must be reached. This is a challenge since the colon is not prepared and the patient is ill. Air insufflation should be minimal in an already distended abdomen. Nonetheless, there are fewer complications with colonoscopy, with a perforation rate of $2 \%$ and mortality of $1 \%$. More aggressive therapies, like percutaneous

Larissa de Oliveira, Gustavo Rengel dos Santos, Gustavo Lenci Marques, Felipe dos Santos Dunin, Viviane de Hiroki Flumignan Zetola and Mauricio Carvalho (2014), International Journal of Case Reports in Medicine, DOI: $10.5171 / 2014.662882$ 
caecostomy, or surgical approach are limited to refractory or complicated cases.

Ogilvie's syndrome is an important differential diagnosis when facing an acute colonic obstruction, especially in critically ill patients. Delaying diagnosis and therapy may result in serious consequences. The reported case aims to underline this importance and to emphasize the available options when supportive and pharmacological treatments are unsuccessful.

\section{References}

1. Arpana, J and Vargas, D. (2012) "Advances and Challenges in the Management of Acute Colonic Pseudo-Obstruction (Ogilvie Syndrome)". Clinics in Colon and Rectal Surgery. 25 (1) 37-45.

2. Aurilio, C, Pace, M.C, Pota, V and Sansone, P. (2012) "Opioid Induced Constipation". Catto-Smith AG, ed. Constipation - Causes, Diagnosis and Treatment [online]. InTech [retrieved march18, 2013] Available: http://cdn.intechopen.com/pdfs/31221/InTe ch-Opioid_induced_constipation.pdf.

3. Choi, J.S, Lim, J.S, Kim, H, Choi, J.Y, Kim, M.J, Kim, N.K, et al. (2008) "Colonic Pseudobstruction: CT findings". American Journal of Roentgenology, 190 (6) 1521-1526.
4. De Giorgio, R and Knowles, C.H. (2009) “ Acute colonic pseudo-obstruction”. British Journal of Surgery 96 (3) 229 - 239.

5. Kayani, B, Spalding, D.R, Jiao, L.R, Habib, N.A and Zacharakis, E (2012) "Does neostigmine improve time to resolution of symptoms in acute colonic pseudoobstruction?" International Journal of Surgery. 10 (9) 453-457.

6. Tsirline, V.B, Zemlyak, A.Y, Avery, M.J, Colavita, P.D, Christmas, A.B, Heniford, B.T, et al. (2012) "Colonoscopy is superior to neostigmine in the treatment of Ogilvie's syndrome". The American Journal of Surgery. 204 (6) 849-855.

7. Vanek, V.W. and Al-Salti, M. (1986) "Acute pseudo-obstruction of the colon (Ogilvie's syndrome). An analysis of 400 cases". Dis Colon Rectum 29(3) 203-210.

8. Wiersema, U. S, Bruno, M.J and Tjwa, E.T.T.L (2013) "On colonoscopy in acute colonic pseudo obstruction". European Journal of Internal Medicine. [online] [retrieved October 21, 2013] Available: http://dx.doi.org/10.1016/j.ejim.2013.06.007

Larissa de Oliveira, Gustavo Rengel dos Santos, Gustavo Lenci Marques, Felipe dos Santos Dunin, Viviane de Hiroki Flumignan Zetola and Mauricio Carvalho (2014), International Journal of Case Reports in Medicine, DOI: $10.5171 / 2014.662882$ 